\title{
Performance of quadrilateral perforated prestressed concrete rafters
}

\author{
Amer F. Izzet, Nazar K. Oukaili and Falah J. Alkhafaji* \\ Engineer, Directorate of AL-Naser Municipality, Directorate of Thi-Qar Municipalities, Thi-Qar Government, Iraq \\ * Corresponding Author: f.rumi1001@ coeng.uobaghdad.edu.iq
}

Submitted: $12-09-2020$

Revised: 13-08-2021

Accepted: 23-08-2021

\begin{abstract}
This study focuses on the behavior of simply supported perforated prestressed concrete rafters (PPCRs) under single midspan monotonic static loading. The experimental program consists of testing seven specimens, one solid (control) rafter, and six perforated quadrilateral openings. The main investigated variables are the number and height of the openings. The test findings indicate that, in comparison to the solid rafter, the presence of quadrilateral openings in the PPCRs led to reducing the load capacity by (4.3-36\%) and increasing the midspan deflection at ultimate by (14.8-33\%). Also, increasing the number of concrete posts between openings resulted in increasing the failure load and decreasing the deflection at all stages of performance of the prestressed concrete rafter. On the other hand, decreasing the depth of the upper and lower chords by $25 \%$ for PPCRs with the same number of openings led to a reduction in the failure load by $36,29.5$, and $24.5 \%$ for rafters with 6,8 , and 10 openings, respectively.
\end{abstract}

Keywords: prestressed concrete rafter; perforated; quadrilateral openings; chord; post.

\section{INTRODUCTION}

Perforated prestressed concrete rafter system (PPCR) has been identified as a superior alternative for the construction of structural concrete long-spanned roofs of a warehouse, industrial buildings, and airplanes hangars due to the relatively low material costs, good reputation of high fire resistance, and low maintenance costs. The advantages of the creation of openings in prestressed concrete rafter (PCR) include achieving geometrical flexibility and ease passage for utilities, facilitating the shipping and erecting process, and significantly reducing the overall weight (Hassan \& Izzet, 2019a); (Hassan \& Izzet, 2019b); (Hassan \& Izzet, 2019c); (Alkhafaji \& Izzet, 2020a); (Alkhafaji \& Izzet, 2020b).

Perforated concrete rafters, whether prestressed or ordinarily reinforced, behave in such a manner as Vierendeel trusses, with contra flexure points occurring almost in the middle of the chord's length. The shear stress in the middle of the opening can be regarded to be distributed within the upper and lower chords relative to their cross-sectional areas, stiffness of the chord, or a compound of these, depending on the cracking propagation in the upper and lower chords (Barney et al., 1977); (Abdalla \& Kennedy, 1995). Provided that the individual chord elements are adequately designed against direct compression or tension failures and shear, the failure of the perforated rafter occurs through the formation of a mechanism consisting of plastic hinges at the ends of the chord elements. However, in the case of prestressed concrete, special care should be taken to the probability of cracking at the opening edges during the transfer of the prestressing force. In reinforced concrete beams, web openings should be placed away from regions of high shear concentration as well as beams in which openings are located in regions of predominant flexural stresses.

The construction of a long-span rafter is incredibly difficult to produce, since concrete is inefficient in tensile strength, it is necessary to add prestressing steel to resist the applied

load and span reinforcement with ordinary steel that only could not be achieved (Samir, 2013). The objective of the present study is to investigate the behavior of perforated prestressed concrete rafters under monotonic static loading up to failure and try to find the optimum number and height of quadrilateral openings. 


\section{DETAILS AND TEST SETUP OF EXPERIMENTAL PROGRAM}

All tested rafters had an overall length of $3000 \mathrm{~mm}$ with a clear span of $2800 \mathrm{~mm}$, a width of $100 \mathrm{~mm}$, and a height of $400 \mathrm{~mm}$ at the center and $250 \mathrm{~mm}$ at the ends; see Figure 1. In Figure 1, the symbol (PG) refers to prestressed gable rafter, the subsequent symbol (B) or (T) denotes solid without openings or with trapezoidalshaped openings, respectively, and the next digit following the symbols represents the number of the created openings. Reinforcement details for the solid rafter are demonstrated in Figure 2. The same details of reinforcement were used for all perforated rafters (Figure 3). The rafters were divided into two groups depending on the opening's height (i.e., cross-sectional depth of the upper and lower chords); see Table 1.

A self-equilibrium steel frame was used to test the rafter specimens. The applied single midspan load was monotonically increased up to failure through a hydraulic jack of $1000 \mathrm{kN}$ capacity. The strain and dial gauges were attached to their specific locations to measure strain and deflection, respectively (Figure 4). The readings of strains and dial gauges were monitored at the end of each load increment. Also, at each loading increment, crack width was fixed, and at the end, the failure load was reported.

\section{MATERIAL PROPERTIES}

The properties of the materials used in this investigation are presented in Table 2. Standard testing of cement and aggregate was carried out in compliance with the Iraq Standard Requirements (IQS) No. 5-2019 and No. 45-1984, respectively, whereas the steel bars were tested according to ASTM A615-2016, ASTM A496-2007, and ASTM416-2017 for steel bars,

deformed steel wire, and the seven-wire low-relaxation strand of $12.7 \mathrm{~mm}$ diameter (Grade $270 \mathrm{ksi}$ ), respectively. The prestressing force was induced from one end jacking applying prestress of $0.60 \mathrm{f}_{\mathrm{pu}}(110 \mathrm{kN})$ according to the limits of ACI-318M-19.

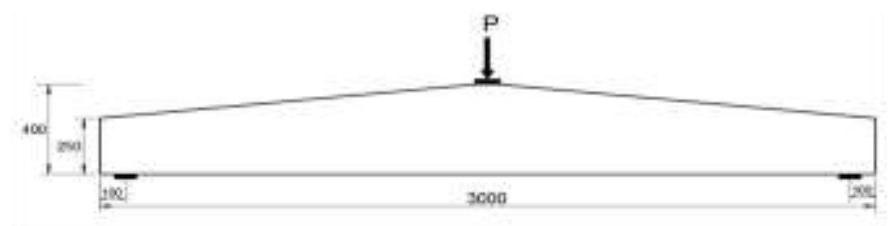

a- beam PGB.

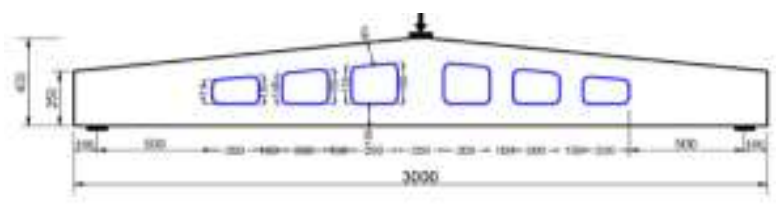

b- beam PGT6.

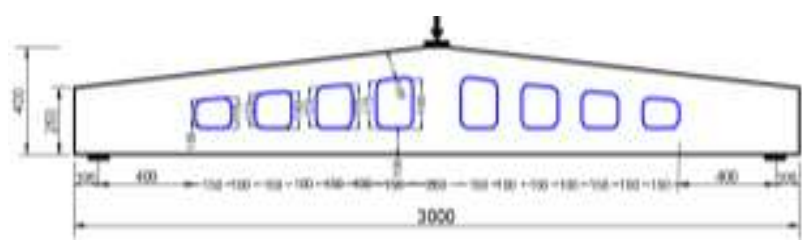

c- beam PGT8.

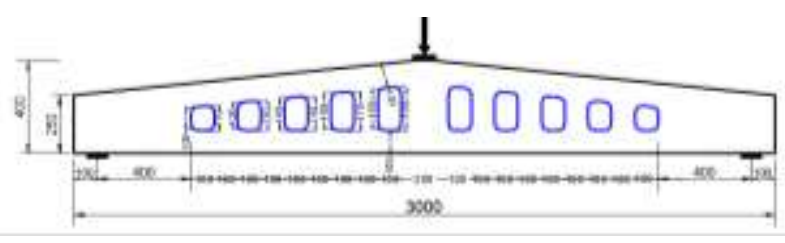

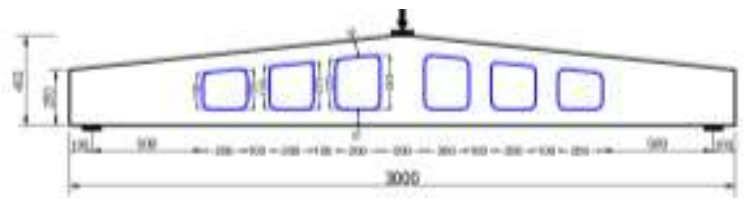

e- beam PGTH6.

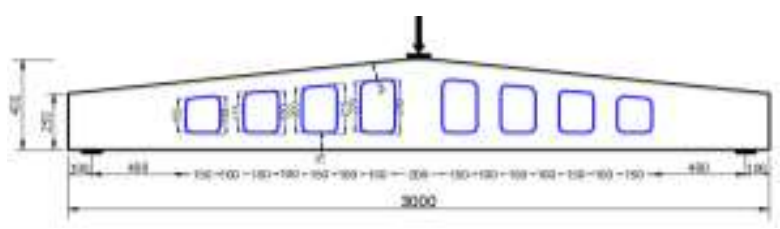

f- beam PGTH8.

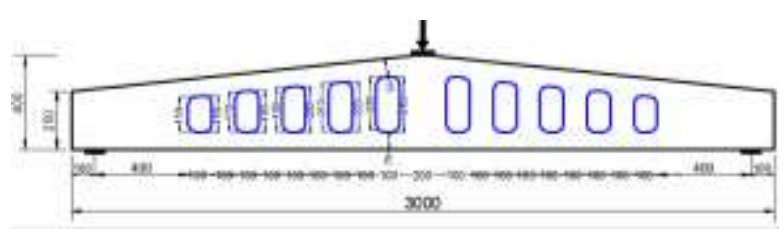


Figure 1. Details of beams (dimensions are in $\mathrm{mm}$ ).

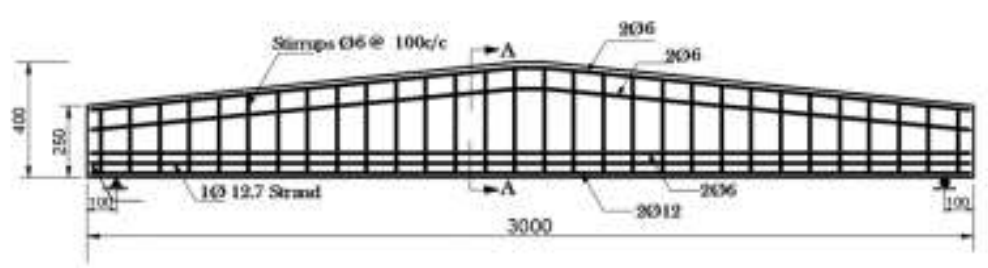

a- Reinforcement details

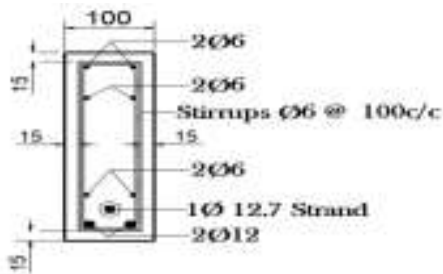

b- Section A-A

Figure 2. Reinforcement details for non-perforated beam PGB ( dimensions are in $\mathrm{mm}$ ).

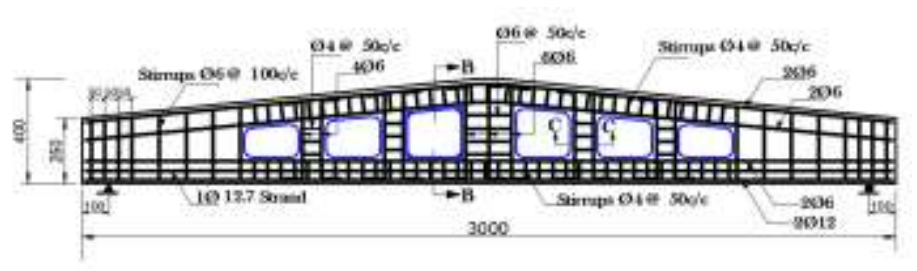

a- Reinforcement details
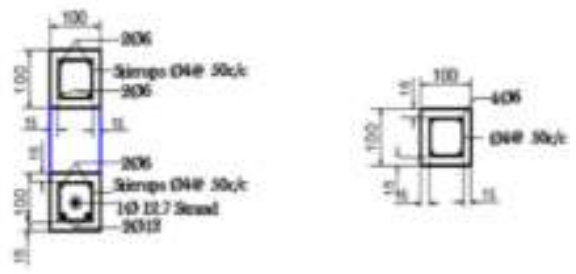

b- Section B-B

c- Section C-C

Figure 3. Reinforcement details for the perforated beam of groups A and B (dimensions are in mm).

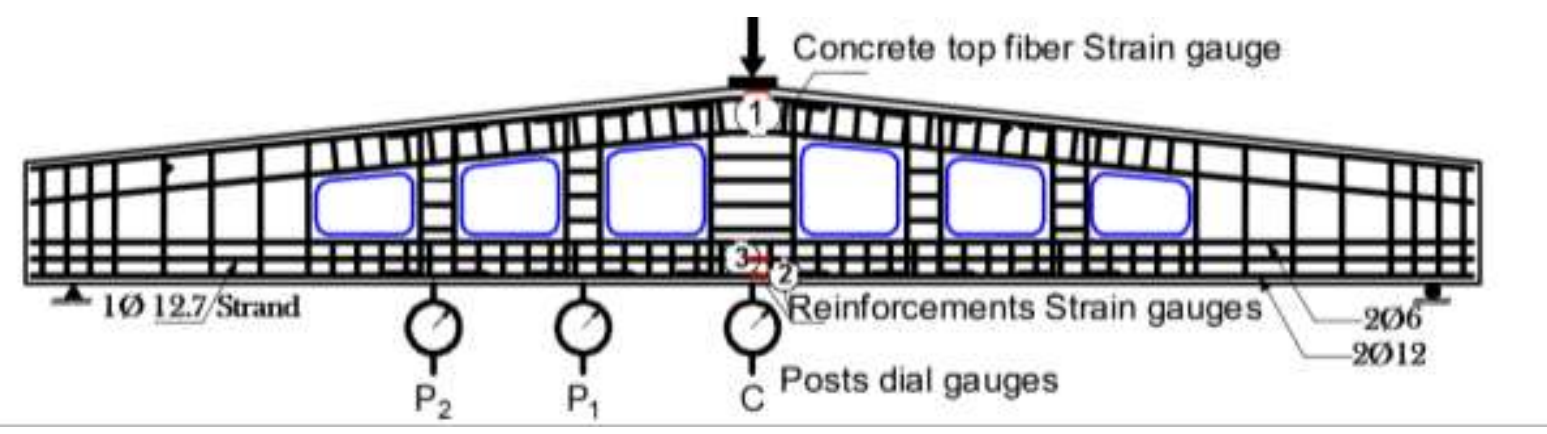

Figure 4. Instrumentation of tested rafters.

Table 1. Details of tested rafters.

\begin{tabular}{|c|l|c|c|c|c|}
\hline \multirow{2}{*}{ Group } & Label & Number & $\begin{array}{c}\text { Total Area of } \\
\text { Opening }\left(\mathbf{m m}^{\mathbf{2}}\right)\end{array}$ & $\begin{array}{c}\text { Width of } \\
\text { Openings } \\
(\mathbf{m m})\end{array}$ & $\begin{array}{c}\text { Height of Upper and } \\
\text { Lower Chords (mm) }\end{array}$ \\
\hline \multirow{2}{*}{ Control } & PGB & solid & - & - & - \\
\hline \multirow{3}{*}{ A } & PGT6 & 6 & 180000 & 200 & 100 \\
\cline { 2 - 6 } & PGT8 & 8 & 174000 & 150 & 100 \\
\cline { 2 - 6 } & PGT10 & 10 & 144000 & 100 & 75 \\
\hline \multirow{2}{*}{ B } & PGTH6 & 6 & 240000 & 200 & 75 \\
\cline { 2 - 6 } & PGTH8 & 8 & 234000 & 150 & 75 \\
\cline { 2 - 6 } & PGTH10 & 10 & 195000 & 100 & 100 \\
\hline
\end{tabular}


Table 2. Properties of materials.

\begin{tabular}{|c|c|c|c|c|c|}
\hline Material & $\begin{array}{l}\text { Diameter, } \\
(\mathbf{m m})\end{array}$ & $\begin{array}{c}\text { Yield } \\
\text { Stress, } \\
(\mathrm{MPa})\end{array}$ & $\begin{array}{c}\text { Average } \\
\text { Compressive } \\
\text { Strength } \\
\left(\boldsymbol{f}_{c}^{\prime}\right), \\
(\mathrm{MPa})\end{array}$ & $\begin{array}{c}\text { Average } \\
\text { Ultimate } \\
\text { Tensile } \\
\text { Strength, } \\
\text { (MPa) }\end{array}$ & $\begin{array}{l}\text { Average } \\
\text { Modulus of } \\
\text { Elasticity, } \\
\text { GPa) }\end{array}$ \\
\hline Strand & 12.7 & 1674 & ------ & 1860 & 197.5 \\
\hline \multirow{3}{*}{ Rebar } & 12 & 600 & ------ & 695 & 200 \\
\hline & 6 & 550 & ------ & 670 & 200 \\
\hline & 4 & 370 & ------ & 650 & 200 \\
\hline Concrete & ------ & ------ & 40.9 & 4.5 & 31.5 \\
\hline
\end{tabular}

\section{EXPERIMENTAL FINDINGS AND DISCUSSION}

\section{LOAD-DEFLECTION RESPONSE}

Three stages of loading were selected to investigate the response of the tested prestressed concrete rafters, mainly, the uncracked elastic stage $(40 \mathrm{kN})$, service stage $(80 \mathrm{kN})$, and ultimate loading stage. Table 3 and Figure 5 reveal that the presence of openings in PPCR increases the deflection at all loading stages. This observation is verified by the incremental ratio of the deflection relative to the PGB. But these ratios decrease in each group with increasing openings number extended at the same beam length. In all groups, the PPCR with ten openings was the closest to that of the PGB, followed by specimens with eight then with six openings. On the other hand, decreasing openings height as in Group A, the rafters behavior approach to PGB, in contrast, a higher deviation was observed for those of Group B. Additionally, the following observations can be driven: PPCRs behaved linearly (elastically) before cracking, and the slope of linear parts was slightly different for specimens of each group. While more cracking has been observed, the behavior gradually changed from linear to nonlinear, and then the slope of the curves of each group was, therefore, substantially deviated.

In comparison to solid rafter PGB, the creation of openings led to increasing the deflection of PPCRs at different stages of loading. The increase of deflection at elastic, service, and ultimate loads ranged between 30.6$90.7 \%, 10.2-84.2 \%$, and $14.8-33.1 \%$, respectively, for PPCRs relative to the solid rafter.

Inserting openings in PPCR reduced the ultimate load capacity. The reduction ratio of the ultimate load capacity for PPCRs varying from 4.3 to $36.1 \%$ in comparison to the nonperforated specimen (PGB).

Another comparative group (Group C) has been classified in Table 3 to reveal the effect of openings height by comparing rafters having the same openings number but differing in openings height (i.e., 25\% variation in chords depth). It can be found that the deflection at midspan was increased with the increase of the height of the opening because the PPCR stiffness is greatly affected by the two chords' depth. The behavior of the specimens in Figure 6 is verifying these observations, where PPCRs with the lesser chord depths have the lesser stiffness.

Deflection along the tested beams at each post (node) has been measured at three loading stages (40, 80 
$\mathrm{kN}$, and ultimate load) as demonstrated in Figure 7. These curves recognize that the high deflection progress was monitored at the first and second posts next to the support. This deflection mainly occurred at the portions between the posts (openings zone) due to the drop in the overall stiffness as a result of the creation of openings.

Table 3. Failure load and deflection at three loading stages of the tested beam.

\begin{tabular}{|c|c|c|c|c|c|c|c|c|c|}
\hline \multirow[b]{2}{*}{$\stackrel{0}{0}$} & \multirow[b]{2}{*}{ 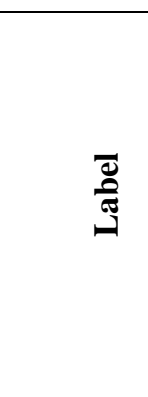 } & \multicolumn{2}{|c|}{ @ 40 kN load } & \multicolumn{2}{|c|}{ @ 80 kN load } & \multicolumn{2}{|c|}{ @ $\mathbf{P}_{\text {ult }}$} & \multirow{2}{*}{ 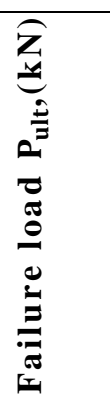 } & \multirow{2}{*}{ 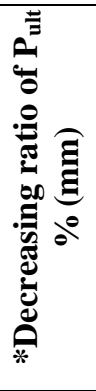 } \\
\hline & & 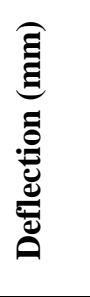 & 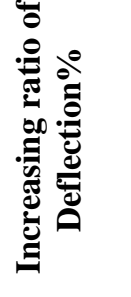 & 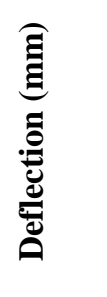 & 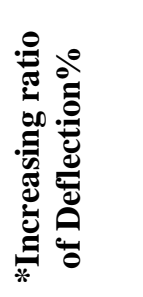 & 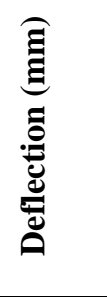 & 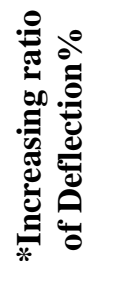 & & \\
\hline Control & PGB & 2.37 & - & 7.88 & - & 20.25 & - & 148.4 & - \\
\hline \multirow{3}{*}{$\mathbf{A}$} & PGT6 & 3.94 & 66.24 & 9.54 & 21.13 & 25.25 & 24.69 & 132.2 & 10.91 \\
\hline & PGT8 & 3.42 & 44.18 & 9.00 & 14.19 & 23.75 & 17.28 & 140.0 & 5.66 \\
\hline & PGT10 & 3.10 & 30.57 & 8.68 & 10.23 & 23.25 & 14.81 & 142.0 & 4.31 \\
\hline \multirow{3}{*}{ B } & PGTH6 & 4.53 & 91.35 & 14.52 & 84.21 & 26.95 & 33.08 & 94.9 & 36.05 \\
\hline & PGTH8 & 4.05 & 70.88 & 11.95 & 51.66 & 26.0 & 28.39 & 104.6 & 29.51 \\
\hline & PGTH10 & 3.59 & 51.47 & 10.63 & 34.90 & 24.5 & 20.98 & 112.0 & 24.52 \\
\hline \multicolumn{10}{|c|}{$(*) \frac{(P P C R)-(P G B)}{(P G B)} \times 100$} \\
\hline \multirow[t]{2}{*}{ CI } & PGT6 & 3.94 & 0 & 9.54 & 0 & 25.25 & 0 & 132.2 & 0 \\
\hline & PGHT6 & 4.53 & 15.4 & 14.52 & 52.0 & 26.95 & 6.7 & 94.9 & 28.2 \\
\hline \multirow[t]{2}{*}{ CII } & PGT8 & 3.42 & 0 & 9.00 & 0 & 23.75 & 0 & 140.0 & 0 \\
\hline & PGTH8 & 4.05 & 17.6 & 11.95 & 32.2 & 26.00 & 9.5 & 104.6 & 25.3 \\
\hline \multirow[t]{2}{*}{ CIII } & PGT10 & 3.10 & 0 & 8.68 & 0 & 23.25 & 0 & 142.0 & 0 \\
\hline & PGTH10 & 3.59 & 12.9 & 10.63 & 22.1 & 24.50 & 5.4 & 112.0 & 21.1 \\
\hline \multicolumn{10}{|c|}{$(*)$} \\
\hline
\end{tabular}

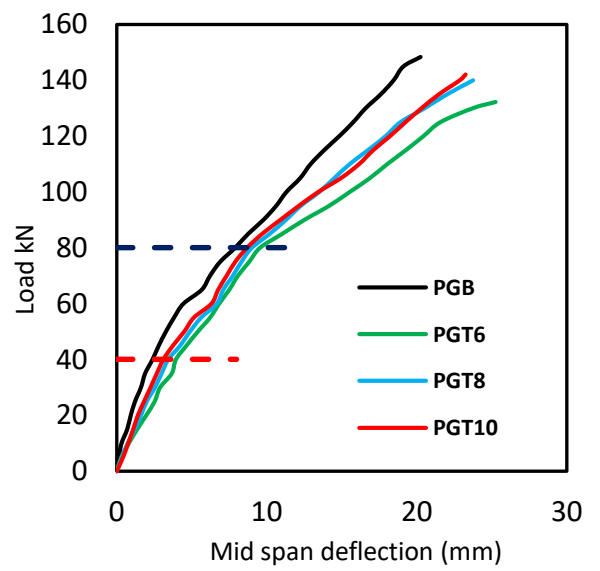

a-Group A

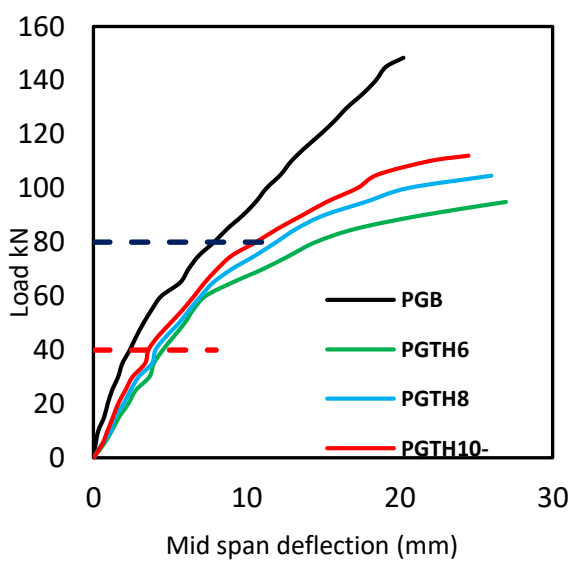

b-Group B

Figure 5. Load-deflection curves for main groups (A) and (B). 


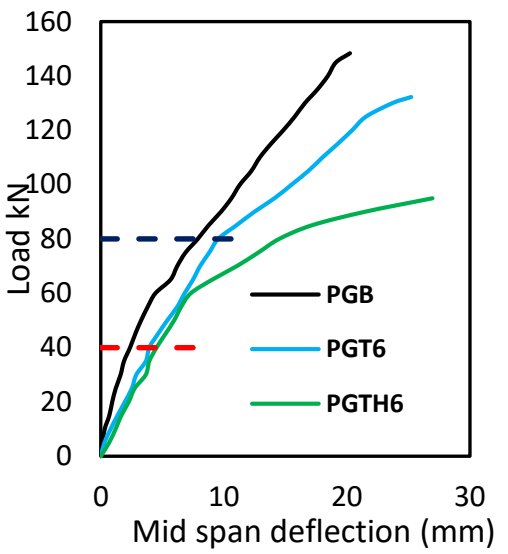

Group CI

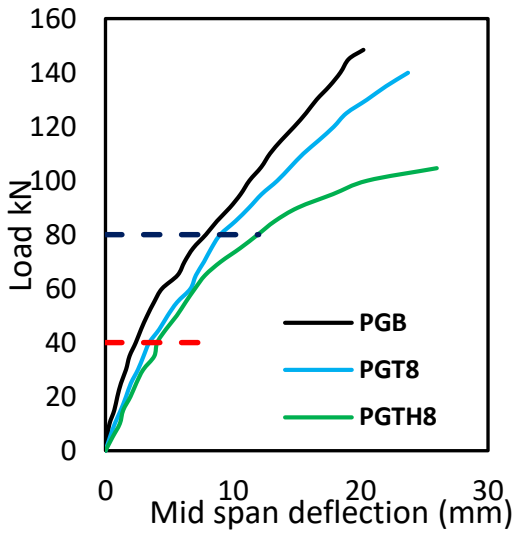

Group CII

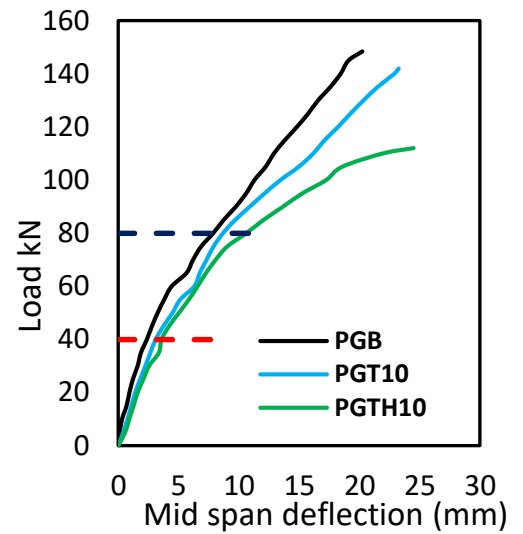

Group CIII

Figure 6. Load-deflection curves for comparitive Group C.

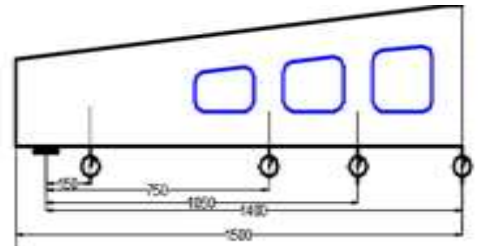

0. $\quad 200 \quad 400 \quad 600 \quad 800 \quad 1000 \quad 1290 \quad 1400$

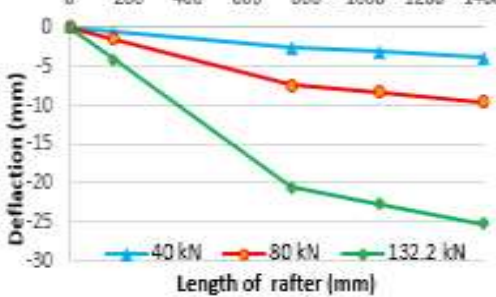

a-PGT6
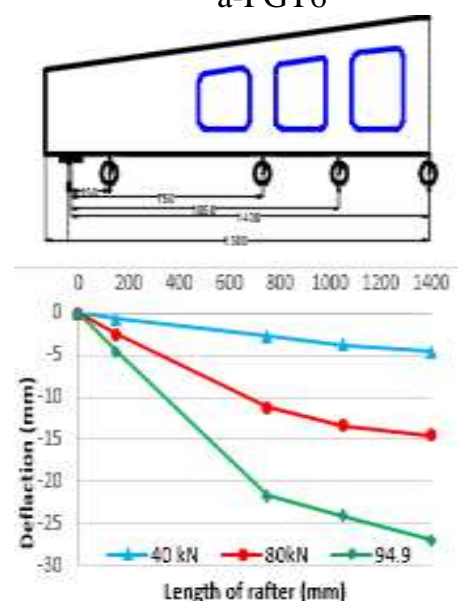

d-PGTH6

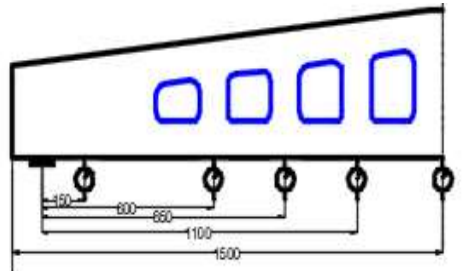

$\begin{array}{llllllll}0 & 200 & 400 & 600 & 800 & 1000 \quad 1200 & 1400\end{array}$

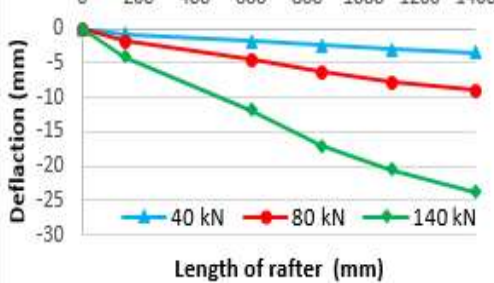

b-PGT8

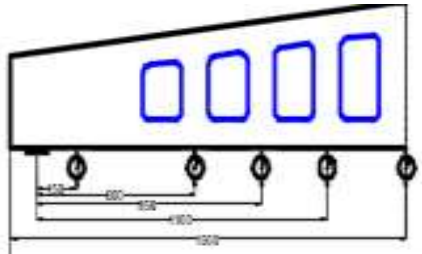

$\begin{array}{lllllll}200 & 400 & 600 & 800 & 1000 & 1200 & 1000\end{array}$

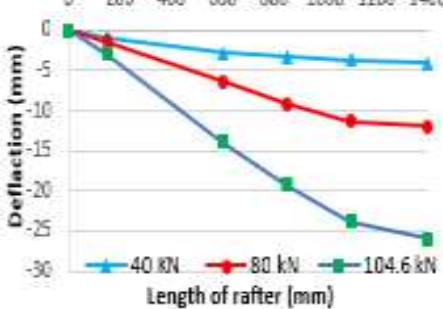

e-PGTH8
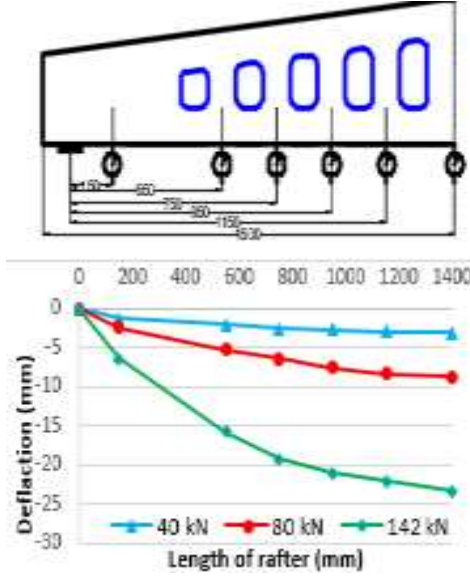

c-PGT10

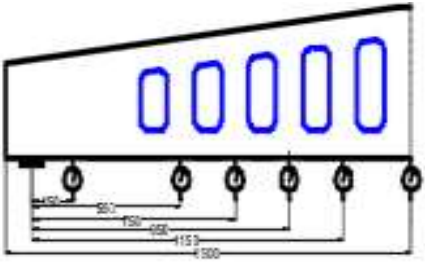

$\begin{array}{lllllll}209 & 400 & 500 & 800 & 1000 & 1200 & 1400\end{array}$

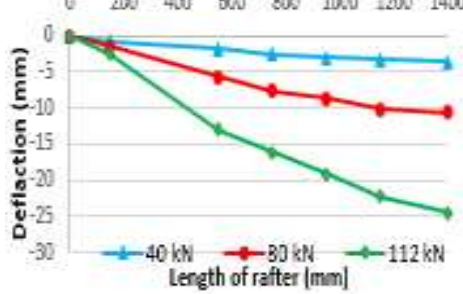

f-PGTH10

Figure 7. Deflection profile of the tested rafters.

\section{MODES of FAILURE}

In the nonperforated rafter (PGB), failure progression started by cracking that initiated from the rafter's soffit, then yielding of the tensile steel reinforcement at midspan zone, followed by cracking propagation towards the upper fibers, and finally compression failure at the extreme top fibers of the concrete near to the point load has 
happened. Four types of cracking patterns were formed in the perforated rafters, mainly, opening corner cracks, shear cracking at chords, flexural cracking in chords, and cracking of tension chord. One of these types of cracking developed and propagated more than the others. Accordingly, various modes of failure due to these cracking patterns were observed. As a result, two different modes of failure happened. The first was a diagonal splitting crack at the corners, where the corner cracks propagated and developed toward the loading point and to the nearest support, followed by compression failure, as in specimens PGT6, PGT8, and PGT10. While the second mechanism of failure was caused by the formation of plastic hinges adjacent to the openings in many of the chords of the rafters, these successive plastic hinges affect the curvature of the beam, followed by posts shear failure. Stresses will, therefore, be redistributed to larger parts of the rafter that participated in the Vierendeel action in flexural strength, such as in rafters PGTH6, PGTH8, and PGTH10. Figures 8, 9, and 10 illustrate the mode of failure and crack patterns for each of the tested beams.

\section{STRAIN DISTRIBUTION}

To detect the behavior via the stress that was generated in the rafter's elements, electrical resistance strain gauges were fixed at different locations and levels of the rafter members, on concrete surface and steel reinforcements (mild steel and strand), as shown in Figure 4.

Figure 11 illustrates, for all rafters, the load versus midspan compressive strain at the concrete top surface (strain gauge number 1) for loading stages of $40,80 \mathrm{kN}$, and the ultimate load.

The following conclusions can be drawn:

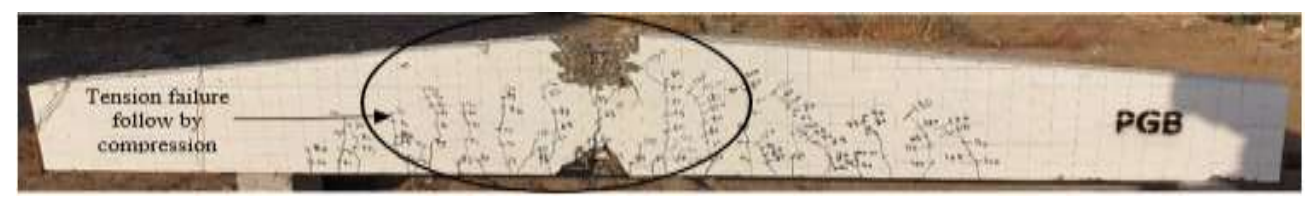

Figure 8. Mode of failure of PGB rafter by yielding in steel reinforcement followed by compression failure.
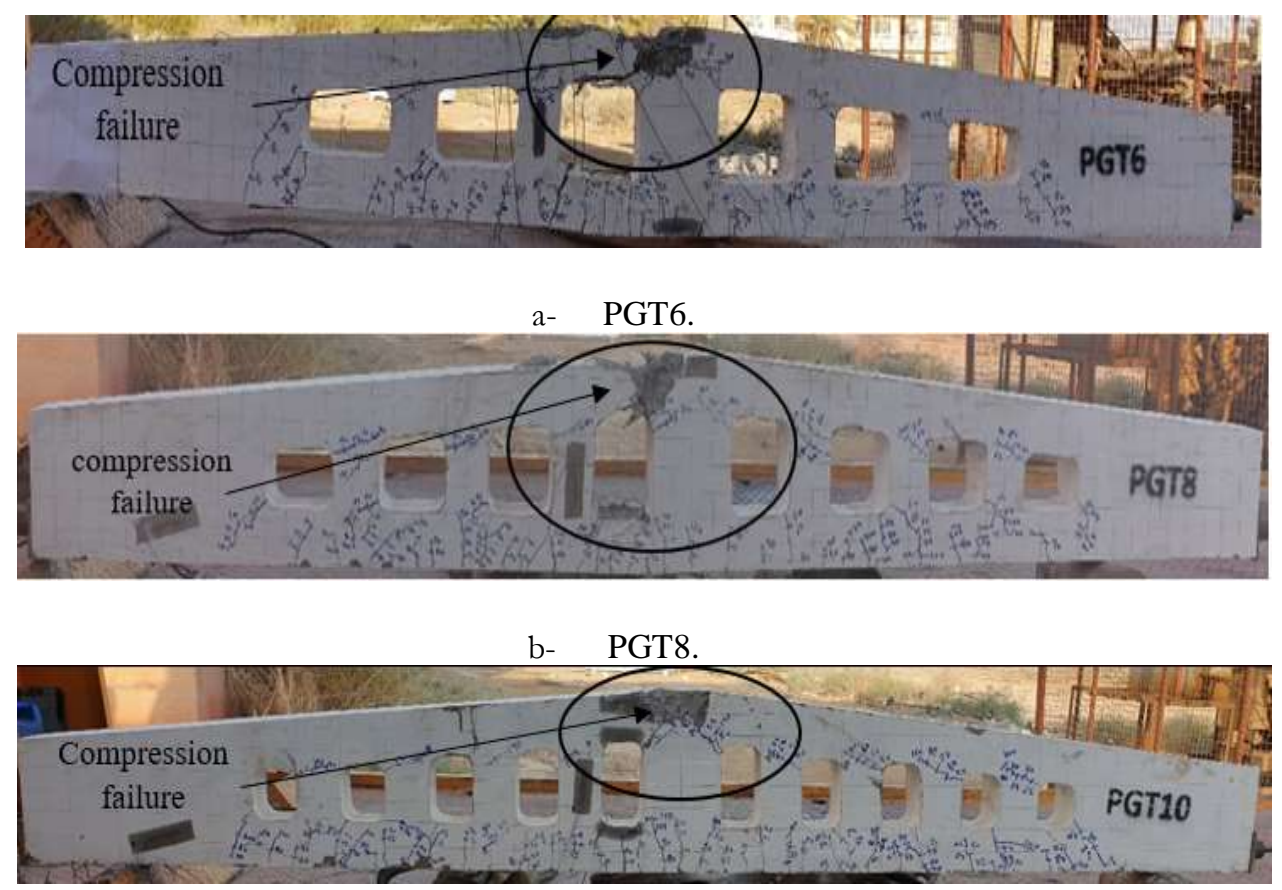

c- PGT10.

Figure 9. Failure mode of Group A rafters by diagonal splitting failure at opening corners followed by compression failure. 

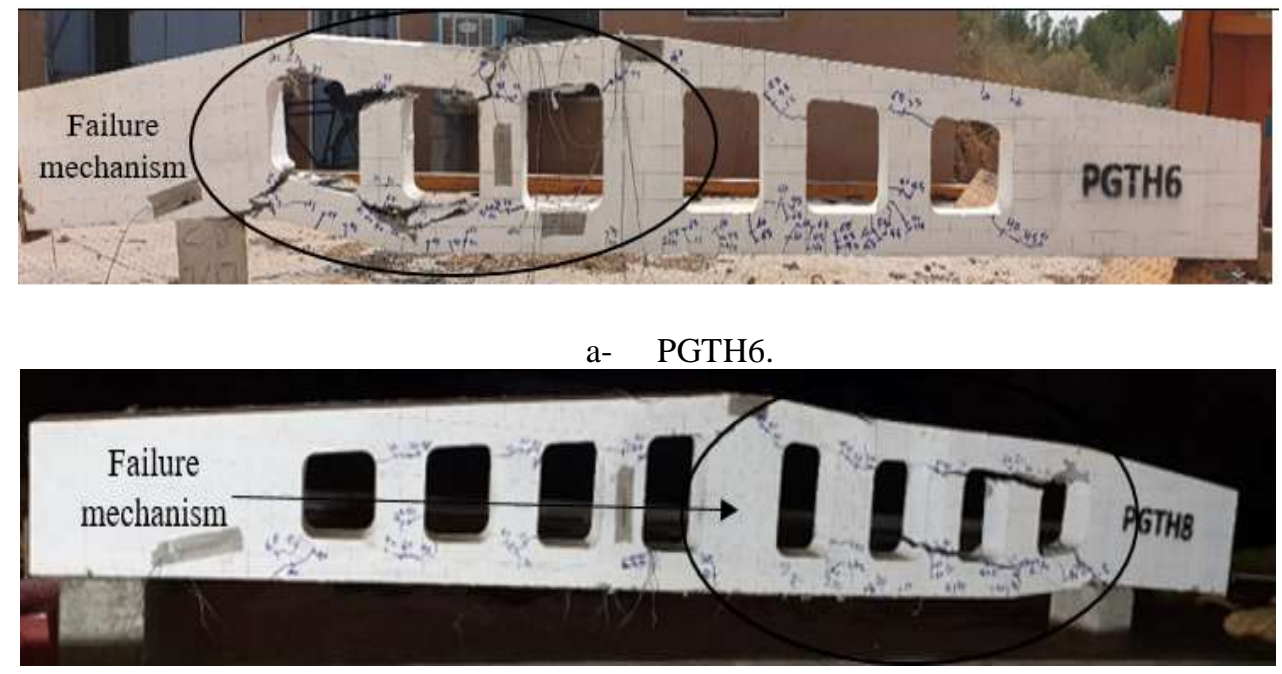

b- PGTH8.

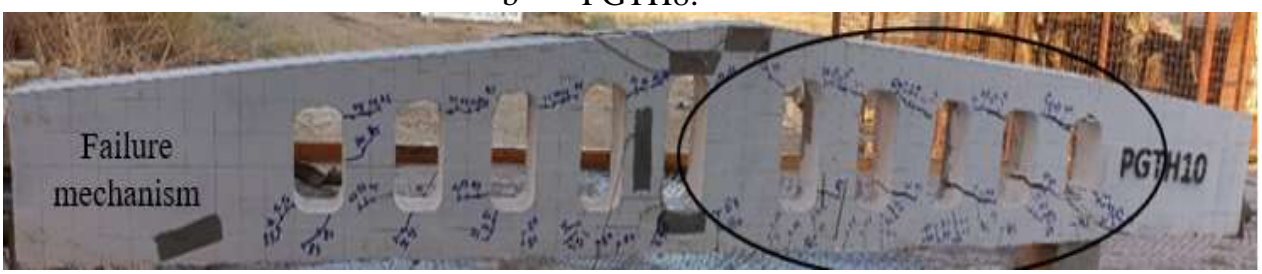

c- PGTH10.

Figure 10. Failure mode of Group B rafters by plastic hinges and posts shear failure.

For the same opening's height (Groups A and B), increasing the number of openings to 8 and 10 led to a decrease in the average concrete compressive strain by 12 and $25 \%$, and 15 and $30 \%$ for loading stages of 40 and $80 \mathrm{kN}$, respectively. This might be due to minimizing the total area of openings and increasing the number of posts, which have a beneficial effect on the strength of the rafter. Figure 12 reveals that differences happened for the rafters with the same number of quadrilateral openings but differ in their height (Groups C). It can be seen that increasing openings height (i.e., decreasing upper and lower chords by 25\%) led to a significant increase in concrete compressive strain for all loading stages.

Strains were measured for the lower layer of steel reinforcement at the midspan section (strain gauge number 2); see Figure 4. Figures 13 and 14 demonstrate the strain in this type of steel, where the presence of openings in the perforated rafter increases the steel bars strains at all loading stages. It can be noticed that the increasing ratio of midspan strain at loading stage $40 \mathrm{kN}$ ranging between $21.6-95.8 \%$ while it was $34.7-11 \%$ at load stage of $80 \mathrm{kN}$ relative to the strain in such steel in the nonperforated specimen. These increments can be interpreted by the fact that the creation of openings in the rafter reduced the cross-sectional area and moment of inertia, which led to a decrease in the rafter's overall stiffness.

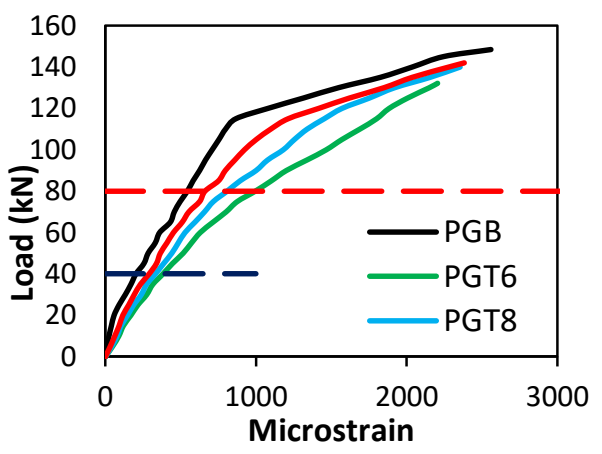

a- Group A

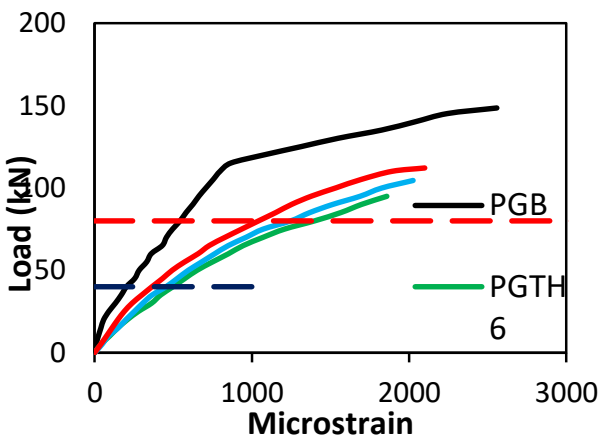

b- Group B 
Figure 11. Load versus midspan compressive strain at top of concrete for groups A and B.

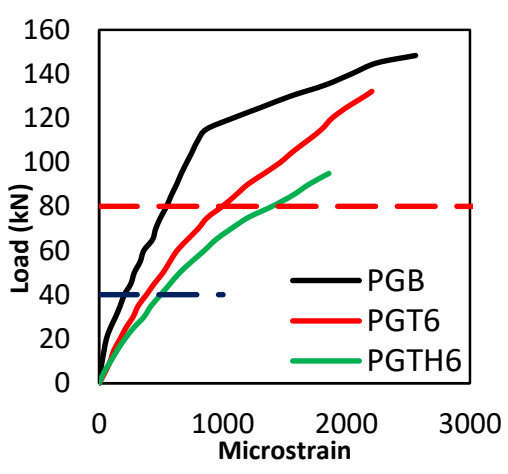

c- Group CI

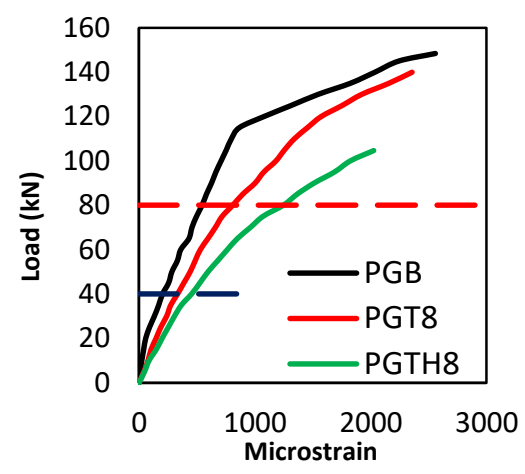

d- Group CII

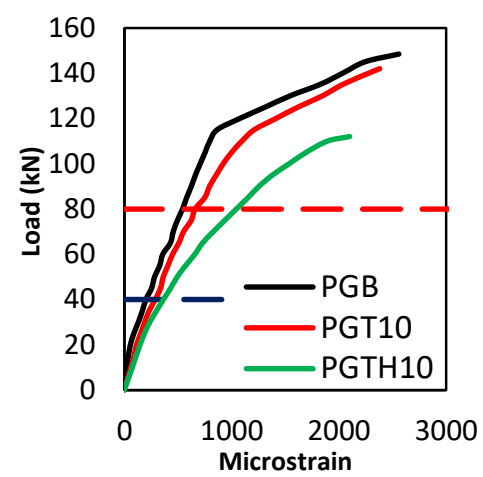

Group CIII

Figure 12. Load-midspan compressive strain in extreme concrete fibers for group C.

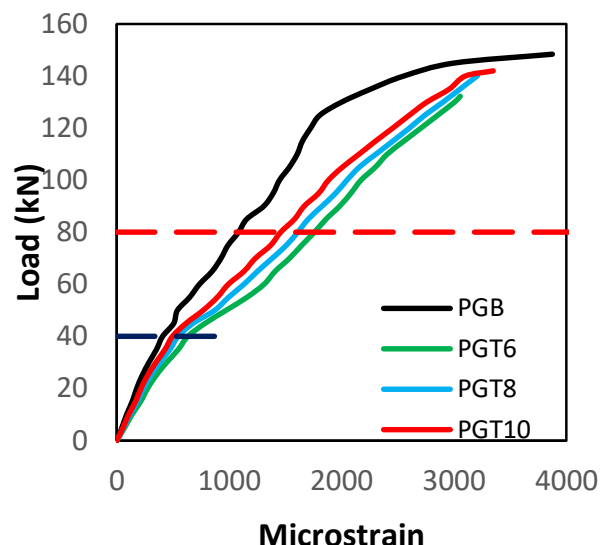

Group A

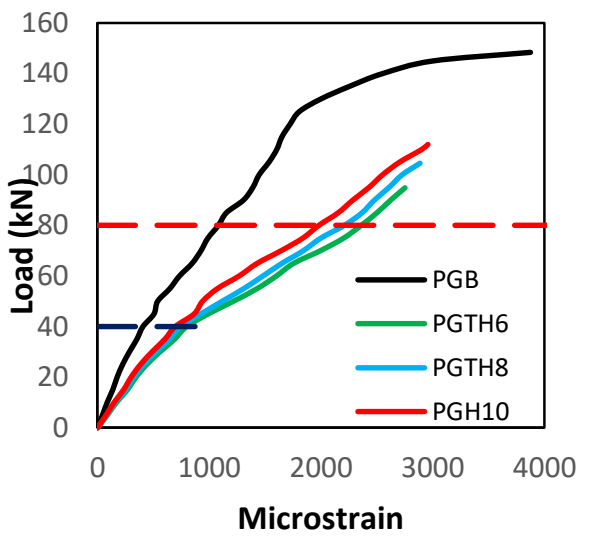

Group B

Figure 13. Load-strain in steel bars for groups A and B.

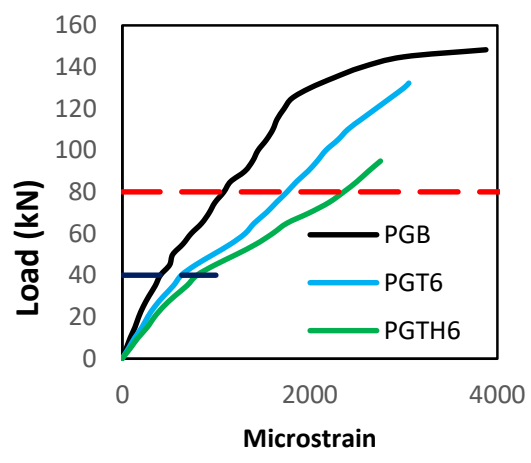

a- $\quad$ Group CI

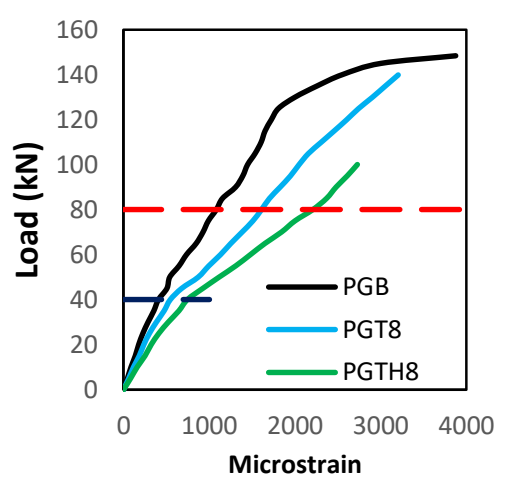

b- Group CII

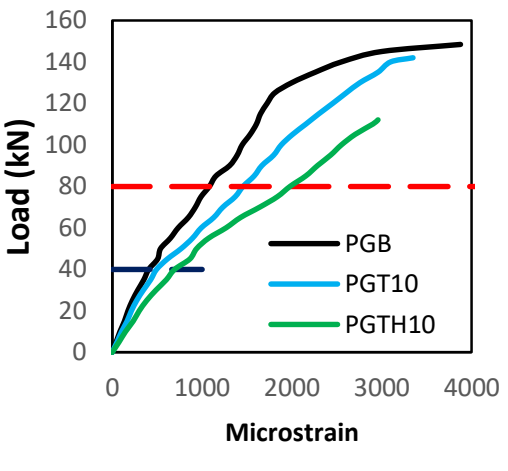

c- $\quad$ Group CIII

Figure 14. Load-strain in steel bar for Group C.

According to the tensile test results for steel reinforcements, which were performed on $12 \mathrm{~mm}$ bars diameter (Table 2), the yielding strain is 3000 Microstrain thus, at ultimate load, the steel in the nonperforated rafter (PGB) yielded, and all perorated rafters also reached this limit or approached to that such as PGTH6, PGTH8, and PGTH10.

The strain in the prestressing strand has been measured using an electrical strain gauge at the midspan section as mentioned earlier (strain gauge number 3); see Figure 4. Table 4 shows effective stresses and strains for 
each rafter before the loading test, the increase in strain at ultimate loading $\Delta \varepsilon_{p s}$, the ultimate strain $\varepsilon_{p s}$, and the stress $f_{p s}$ in the strand of each prestressed rafters. Figures 15 and 16 illustrate load versus strain in prestressed steel for all rafters depending on the classified groups.

The following findings may be noticed from the test results:

For the nonperforated rafter, the stress nearby the failure stage in prestressing strands exceeded their yielding strength limit $\left(0.9 f_{p u}\right)$. Meanwhile, the mode of failure for these rafters was tension followed by compression failure near the load point. In contrast, the other rafters, the stresses at the failure stage in prestressing strands, did not reach the yielding stress limit $\left(0.9 f_{p u}\right)$.

Related to the measured strain in the prestressing strand in PGB, the highest deviation was observed in the perforated rafters of Group B when the two chords' depths decreased by $25 \%$. This may be due to the reduction that happened in the rafter's stiffness, followed by less deviation from the rafters of Group A.

Table 4. Experimental strain and stress in prestressing strand.

\begin{tabular}{|c|c|c|c|c|c|}
\hline $\begin{array}{l}\text { Rafter's } \\
\text { labeling }\end{array}$ & $\begin{array}{c}\text { Effective } \\
\text { prestrain }\left(\varepsilon_{p e}\right) \\
\text { Microstrain }\end{array}$ & $\begin{array}{c}\text { Effective } \\
\text { prestress }\left(f_{p e}\right), \\
(M P a)\end{array}$ & $\begin{array}{c}\text { Strain increment at } \\
\text { failure }\left(\Delta \varepsilon_{p s}\right) \\
\text { Microstrain }\end{array}$ & $\begin{array}{c}\text { Total strain at } \\
\text { failure }\left(\varepsilon_{p s}\right) \\
\text { Microstrain }\end{array}$ & $\begin{array}{c}\text { Total stress at } \\
\text { failure }\left(f_{p e}\right), \\
(M P a)\end{array}$ \\
\hline PGB & 4663.747 & 921.09 & 3921.230 & 8584.977 & 1695.533 \\
\hline PGT6 & 4546.925 & 898.018 & 2442.254 & 6989.179 & 1380.363 \\
\hline PGT8 & 4575.154 & 903.593 & 3005.542 & 7580.696 & 1497.187 \\
\hline PGT10 & 4594.739 & 907.461 & 3108.883 & 7703.622 & 1521.465 \\
\hline PGTH6 & 4503.038 & 889.350 & 1775.251 & 6278.289 & 1239.962 \\
\hline PGTH8 & 4528.000 & 894.280 & 1930.254 & 6458.254 & 1275.505 \\
\hline PGTH10 & 4542.091 & 897.063 & 2012.254 & 6554.345 & 1294.483 \\
\hline
\end{tabular}

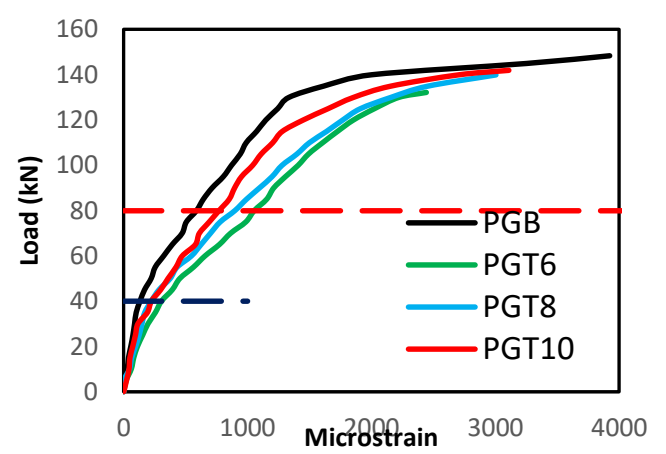

d- Group A

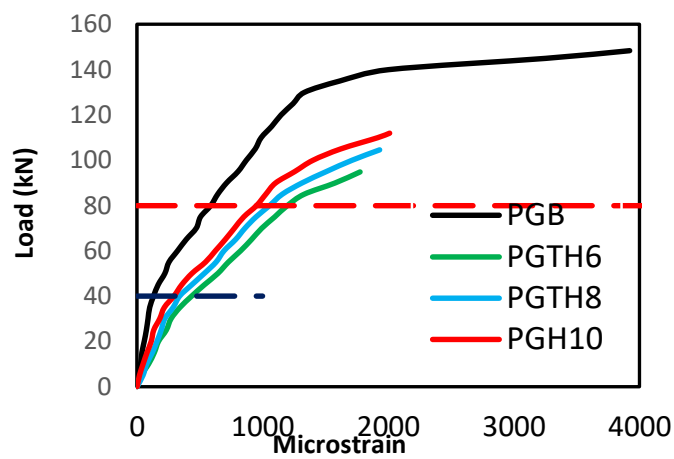

e- Group B

Figure 15. Load versus strain in prestressing steel of main Groups (A and B). 


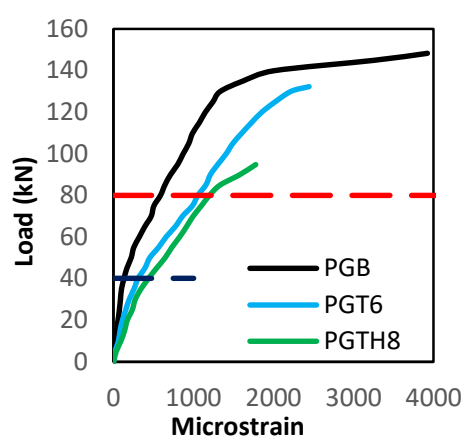

f- $\quad$ Group CI

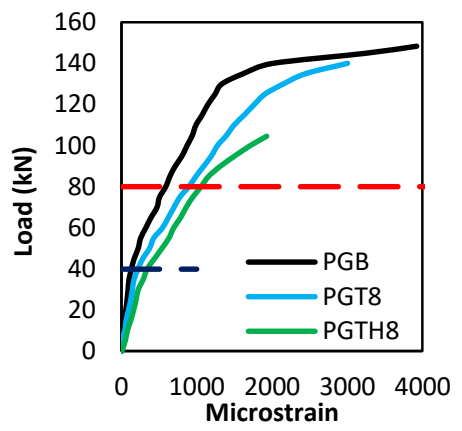

g- $\quad$ Group CII

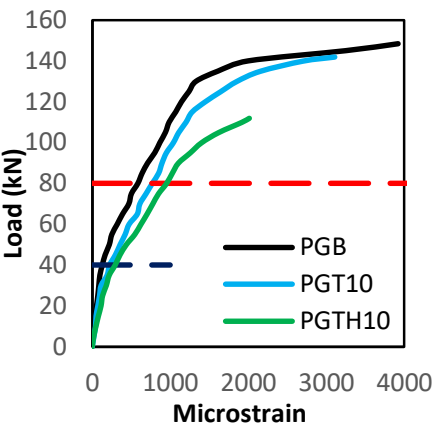

Ggroup CIII

Figure 16. Load versus strain in prestressing steel strand of Group C.

\section{CONCLUSION}

1. Insertion openings in PCR decrease its ultimate load-carrying capacity. This reduction ranges between 4.31 and $36.1 \%$.

2. Conversely, increasing openings number from six to eight and ten extending over the same distance (i.e., increasing posts number) increases the load-carrying capacity of the tested rafters.

3. The increasing percentage of midspan deflection at elastic, service, and ultimate loads ranges between 30.690.7\%, 10.2-84.2\%, and 14.8-33.1\%, respectively, for PPCRs compared to the reference specimen PGB.

4. Moreover, increasing the number of openings from six to eight and ten extending over the same distance (i.e., increasing posts number) decreases the deflection at all loading stages (elastic, service, and ultimate).

5. Decreasing the depth of both upper and lower chords of openings by $25 \%$ for PPCRs having the same openings number led to a reduction in ultimate load-carrying capacity by $36.1,29.5$, and $24.5 \%$ for beams with 6,8 , and 10 openings, respectively, accompanied with an increase in midspan deflection between $90.7-51.1 \%, 84.2-34.9 \%$, and $33.086-21.0 \%$, respectively, at the three loading stages.

6. The mode of failure of specimens of group A was by diagonal splitting cracking at corners of opening; however, increasing openings height in group B changed the mode of failure to a formation of plastic hinges, which led to shear posts failure.

\section{REFERENCES}

ACI Committee 318 (2019). Building code requirements for structural concrete, (ACI 318M-19) and commentary (318R-19). American Concrete Institute, Farmington Hills, Michigan, USA.

Abdalla, H., \& Kennedy, J. B. (1995). Design Against Cracking at at Openings in Prestressed Concrete Beams. PCI journal, 40(6), 60-75.

Alkhafaji, F. J., \& Izzet, A. F. (2020a). Experimental and Numerical Comparison of Prestressed Perforated Concrete Rafters of Different Configurations. In IOP Conference Series: Materials Science and Engineering (Vol. 888, No. 1, p. 012080). IOP Publishing.

Alkhafaji, F. J., \& Izzet, A. F. (2020b). Prestress Losses in Concrete Rafters with Openings. Engineering, Technology \& Applied Science Research, 10(2), 5512-5519.

Barney, G. B., Corley, W. G., Hanson, J. M., \& Parmelee, R. A. (1977). Behavior and Design of Prestressed Concrete Beams with Large Web Openings. PCI Journal, 22(6), 32-61.

Hassan, M. A. J., \& Izzet, A. F. (2019a). Experimental and Numerical Comparison of Reinforced Concrete Gable Roof Beams with Openings of Different Configurations. Engineering, Technology \& Applied Science Research 9(6), 5066-5073. 
Hassan, M. A. J., \& Izzet, A. F. (2019b). Finite element modeling of RC gable roof beams with openings of different sizes and configurations. Mechanics of Advanced Materials and Structures, Vol. 26, 1-17.

Hassan, M. A. J., \& Izzet, A. F. (2019c). Serviceability of Reinforced Concrete Gable Roof Beams with Openings under Static Loads. Engineering, Technology \& Applied Science Research 9(5), 4813-4817.

Samir, P. S. (2013). Precast Prestressed Concrete Truss-Girder for Roof Applications. MSc Thesis, University of Nebraska, Lincoln. 